\title{
Ex-Utero Intrapartum Treatment (EXIT): indications and outcome in fetal cervical and oropharyngeal masses
}

\author{
Lutgardo García-Díaz , Angel Chimenea ${ }^{1,2}$, Juan Carlos de Agustín ${ }^{3}$, Antonio Pavón ${ }^{4}$ and Guillermo Antiñolo ${ }^{1,25^{*}}$ (D)
}

\begin{abstract}
Background: The "Ex-Utero Intrapartum Treatment" (EXIT) procedure allows to ensure fetal airway before completion of delivery and umbilical cord clamping while keeping uteroplacental circulation. Airway obstruction in fetal oropharyngeal and cervical masses can be life-threatening at birth. In those situations, controlled access to fetal airway performed by a trained multidisciplinary team allows safe airway management, while feto-maternal circulation is preserved. We aim to review the indications and outcome of the EXIT procedure in a case series of fetal cervical and oropharyngeal masses.
\end{abstract}

Methods: We have carried out a retrospective review of all patients with fetal cervical and oropharyngeal masses who underwent an EXIT procedure between 2008 and 2019. Variables evaluated included indication for EXIT, ultrasound and MRI findings, the need of amnioreduction, gestational age at EXIT, birth weight, complications, operative time, survival rate, pathological findings, and postnatal evolution. Five patients are included in this series. One additional case has already been published.

Results: The diagnosis were cervical teratoma $(n=1)$, epulis $(n=1)$ and lymphangioma $(n=3)$. Polyhydramnios was present in 2 patients, requiring amnioreduction in one of them. Mean gestational age at EXIT was 36-37 weeks (range, 34-38 weeks). Median EXIT time in placental support was 9 min (range, 3-22 min). Access to airway was successfully established in EXIT in all cases. All children born by EXIT are currently healthy and without complications.

Conclusion: The localization and characteristics of the mass, its relationship to the airway, and the presence of polyhydramnios seem to be major factors determining indications for EXIT and clinical outcome.

Keywords: Fetal surgery, Ex-Utero Intrapartum treatment (EXIT), Placental support, Fetal airway, Airway management, Neck mass

\section{Background}

The "Ex-Utero Intrapartum Treatment" (EXIT) procedure allows ensuring fetal airway before completion of

\footnotetext{
*Correspondence: gantinolo@us.es

1 Department of Materno-Fetal Medicine, Genetics, and Reproduction, Institute of Biomedicine of Seville (IBIS), Hospital Universitario Virgen del Rocio/CSIC/University of Seville, Avda. Manuel Siurot s/n ES-41013, Seville, Spain

${ }^{2}$ Fetal, IVF and Reproduction Simulation Training Centre (FIRST), Seville, Spain Full list of author information is available at the end of the article
}

delivery and umbilical cord clamping while keeping uteroplacental circulation. Although EXIT was initially designed to reverse tracheal occlusion performed on fetuses with a severe congenital diaphragmatic hernia, its indications have expanded over the years [1-3].

Airway obstruction in fetal oropharyngeal and cervical masses can be life-threatening at birth. Nowadays, prenatal diagnosis of fetal anomalies allows anticipating an emergent situation, with high fetal morbidity and

(c) The Author(s). 2020 Open Access This article is licensed under a Creative Commons Attribution 4.0 International License, which permits use, sharing, adaptation, distribution and reproduction in any medium or format, as long as you give appropriate credit to the original author(s) and the source, provide a link to the Creative Commons licence, and indicate if changes were made. The images or other third party material in this article are included in the article's Creative Commons licence, unless indicated otherwise in a credit line to the material. If material is not included in the article's Creative Commons licence and your intended use is not permitted by statutory regulation or exceeds the permitted use, you will need to obtain permission directly from the copyright holder. To view a copy of this licence, visit http://creativecommons.org/licenses/by/4.0/ The Creative Commons Public Domain Dedication waiver (http://creativecommons.org/publicdomain/zero/1.0/) applies to the data made available in this article, unless otherwise stated in a credit line to the data. 
mortality at birth, by planning the end of the pregnancy. In those situations, controlled access to fetal airway performed by a trained multidisciplinary team allows safe airway management, while feto-maternal circulation is preserved.

The aim of this report is to present our experience with EXIT procedure for the management of fetuses with those pathologies, as well as to review clinical criteria to indicate an EXIT procedure in fetal cervical and oropharyngeal masses.

\section{Methods}

We have carried out a retrospective review of the EXIT procedures related to cervical or oral tumors performed at our Department between January 2008 and December 2019 ( $n=5$, in addition to a case previously published by our team) [4]. Our EXIT surgical approach is

Table 1 Summary of the EXIT surgical technique in our Department

\section{EXIT DESCRIPTION}

1. Personnel: Multidisciplinary team including anesthesiologists, pediatric surgeons, neonatologists, maternal-fetal medicine specialists, and operating room nurses.

2. Maternal anesthesia: Deep general anesthesia is used, in addition, an epidural catheter is placed to facilitate postoperative pain management of the mother. General anesthesia induction (remifentanil, propofol and rocuronium) is followed in rapid sequence by intubation and assisted ventilation. Before the uterine incision, deep inhalational anesthesia with sevoflurane is used to maintain uterine relaxation and preserve uteroplacental circulation and fetal gas exchange.

\section{Access to the uterine cavity:}

a. Low transverse laparotomy.

b. Once the uterus is exposed, intraoperative sterile ultrasonography is used to

c. map, carefully, the position of placenta and fetus.

$\mathrm{d}$. The location of the hysterotomy is determined by the placental locations, and a margin of at least $5 \mathrm{~cm}$ from the lower placental edge is left.

e. Uterine progressive distractor, Satinsky vascular clamps, and a stapling device (Premium Poly Cs-57 Autosuture ${ }^{\circledast}$ ) are used in this

order to enter into the amniotic sac with minimum uterine bleeding (Fig. 1)

f. Amnioinfusion with Rintgen's solution is performed to keep uterine volume.

4. Fetal exposure: A gentle fetal extraction with the help of a singleuse suction vacuum (Kiwi@) is performed and the fetus is exposed to the shoulders.

5. Fetal airway management: Fetal anesthesia is supplemented by an intramuscular shot (fentanyl, vecuronium, and atropine) immediately after fetal exposure. Then, the fetal head is positioned to allow access to the airway by direct laryngoscopy or bronchoscopy.

6. Delivery: Once the fetal airway management is completed and secured, the umbilical cord is clamped and divided. The placenta is delivered, the uterine tone is restored (carbetocin plus oxytocin). Finally, uterus and maternal abdominal wall are closed similar to a cesarean section. described in Table 1. Clinical data and fetal as well as maternal outcomes are summarized in Table 2.

\section{Case 1}

A 28-year-old patient, gravida 1, was referred to our center at 37 weeks for evaluation of a cervical mass. 2-D, 3$\mathrm{D}$, and 4-D ultrasound revealed a homogeneous mass of $6.5 \times 5 \times 5 \mathrm{~cm}$ in the fetal neck, suggestive of a cervical teratoma with tracheal displacement. Amniotic fluid was normal.

The patient underwent an EXIT procedure at 38 weeks' gestation. The airway was secured by conventional intubation with an endotracheal tube. Time in placental support was $6 \mathrm{~min}$. The newborn weighed $3407 \mathrm{~g}$.

At $12 \mathrm{~h}$ of life, the patient underwent a left cervicolateral mass resection and left hemithyroidectomy without complications, but required mechanical ventilation $48 \mathrm{~h}$ following intervention due to marked inspiratory stridor consistent with laryngotracheomalacia. Histopathological diagnosis was immature benign teratoma. Mother was discharged on the fourth day after intervention. Annual monitoring is being performed without evidence of relapsed pathology. The child is currently healthy and without complications at the age of 11 .

\section{Case 2}

A 37-year-old patient, gravida 2, para 1, was referred to our center for evaluation of an oropharyngeal fetal mass at 34 weeks. 2-D, 3-D, and 4-D ultrasound revealed a lobulated, solid tumor of $3,7 \times 3,6 \mathrm{~mm}$ with a thick pedicle dependent on the upper jaw and left nostrils not affecting the fetal neck. Amniotic fluid was normal.

The patient underwent an EXIT procedure at 37 weeks. Fetal airway was secured using a flexible laryngofiberscope. Time in placental support was $3 \mathrm{~min}$.

The newborn weighed $3100 \mathrm{~g}$. In the following hours the tumor, pedicled to the premaxilla gingiva, was resected. Histopathological diagnosis was congenital granular epulis.

Mother was discharged on the fourth day after intervention. The child is currently healthy and without complications at the age of 5 .

\section{Case 3}

A 30-year-old patient, gravida 1 was referred to our hospital at 33 weeks for evaluation of a facial and cervical fetal tumor. 2-D, 3-D, and 4-D ultrasound showed a giant cervical lymphangioma. MRI confirmed the diagnosis of a large lymphangioma with tracheal and esophageal compression and displacement. Mild polyhydramnios was present.

At 36 weeks the patient underwent an EXIT procedure. Fetal airway was secured by conventional intubation 


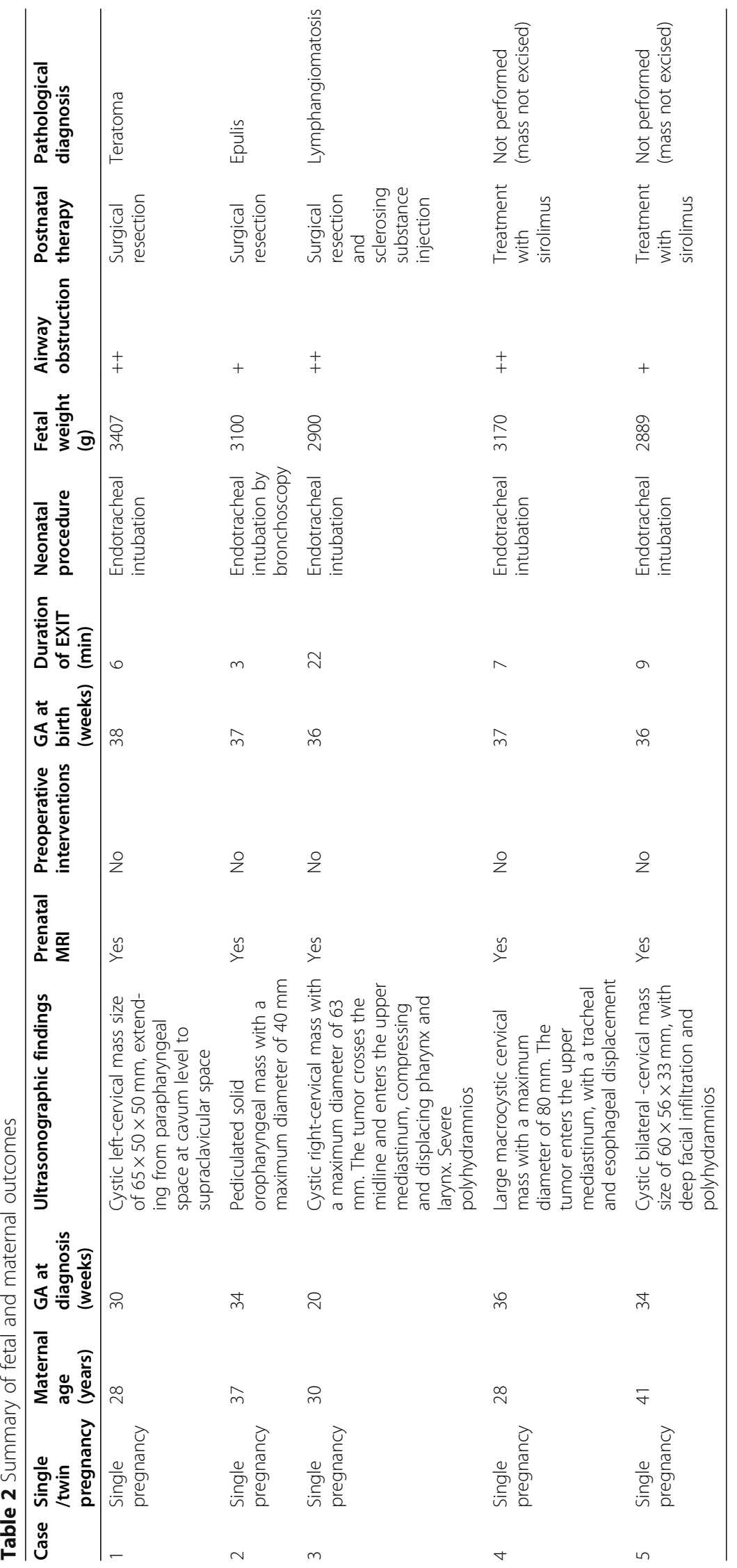


with an endotracheal tube. Time in placental support was $22 \mathrm{~min}$. The newborn weighed $2900 \mathrm{~g}$. On the fifth day of life tumor was partially resected. Injection of sclerosing substances (doxycycline and OK432) was subsequently performed, as well as medical treatment with sildenafil to complete therapy. Despite treatment, at 3 months of age, a respiratory failure developed, requiring a tracheostomy, which was eventually closed at 18 months of age. The mother was discharged on the fourth day after intervention. The child is currently healthy and without complications at the age of 3 .

\section{Case 4}

A 28 -year-old patient, gravida 1, was referred at $36+4$ weeks for evaluation of a large cervical lymphangioma. By 2-D, 3-D, and 4-D ultrasound a large and macrocystic cervical lymphangioma, with a maximum diameter of 8 $\mathrm{cm}$, was observed. The MRI confirmed the lymphangioma extending up to the mediastinum, as well as tracheal and esophageal displacement. Amniotic fluid was normal.

Exit surgery was performed in week $37+6$ days. The airway was secured using a flexible laryngo-fiberscope. Time in placental support was $7 \mathrm{~min}$. Newborn weight was $3170 \mathrm{~g}$. The neonate started treatment with sirolimus $(0.04 \mathrm{mg} / \mathrm{m} 2$ /day) on the 10th day of life and was successfully extubated at 11 days of life. In this case, no surgical resection was performed.

Mother was discharged on the fourth day after intervention. The patient is currently 6 months old and is being followed by the Pediatric Surgery Department. The child has not needed additional therapy, and his evolution is being good.

\section{Case 5}

A 41-year-old patient, gravida 3 para 2, was referred to our department at 34 weeks for evaluation of a large bilateral cervical cystic lymphangioma with polyhydramnios. Ultrasound scan confirmed a large and macrocystic lymphangioma in the face and the neck. MRI showed a complex cystic lymphangioma with deep facial infiltration and polyhydramnios.

After lung maturation with betamethasone, EXIT was performed in week 36 . Airway was secured with flexible laryngo-fiberscope. Time in placental support was $9 \mathrm{~min}$. Newborn weight was $2889 \mathrm{~g}$. The neonate was successfully extubated on the 7th day of life, and treatment with sirolimus was started from the 8th day of life. In this case, no surgical resection was performed.

Mother was discharged on the fourth day after intervention. The newborn was discharged at 22 days of life. The patient is currently 6 months and is being followed by the Pediatric Surgery Department. The boy has not needed additional therapy, and his evolution is being good.

\section{Discussion}

2D, 3D, 4D ultrasound technologies are currently the basis for the diagnosis of different fetal pathologies, including cervical and oropharyngeal tumors as described in our series and other reported cases [5]. In addition, fetal-MRI with a specific sequence can help to improve the information provided by fetal ultrasound [6].

Fetal cervical and oropharyngeal tumors represent very rare entities, whose major problems may be related to the invasion of facial, pulmonary, or central nervous system structures, with the consequent development of polyhydramnios and fetal hydrops. Also, newborns may present an airway obstruction and/or injury due to an intrinsic lesion in the larynx or trachea, or related to an external compression that oropharyngeal or neck masses may produce [2, 4, 7-10]. For that reason, the EXIT procedure has become a standard of care in those cases and may determine the outcome and survival of newborns with different pathologies affecting fetal airway [11-16]. Thus, an increasing trend to the use of EXIT surgery to secure the airway in fetuses with potentially lifethreatening upper airway obstruction can be observed.

Due to potential maternal and fetal risks a careful assessment is necessary before EXIT surgery indication [5, 9, 17-20]. When approached properly by a trained team, EXIT is a safe procedure for mother and fetus. In our surgical technique, summarized in Table 1, a major issue is to secure atraumatic access to the uterine cavity and amniotic sac (Fig. 1) to allow a safe and stable maternal clinical condition during EXIT time.

Novoa et al. [21] recently published a systematic review of the literature evaluating the results of the EXIT surgery in neonatal management of fetal upper airway obstruction. The authors report a fetal or neonatal death rate of $17 \%$ (40/235), with an overall fetal adverse event rate of $29.2 \%$. The overall rate of maternal adverse events was $9.4 \%$. These data contrast with those presented in our series of cases, as in our previously published case [4], in which no adverse fetal event occurred, requiring blood transfusion exclusively in one of the cases. The time until maternal discharge was 4 days, similar to that found in a conventional cesarean section in our Department.

\section{Conclusions}

In our experience and others [2, 4, 17-20], in fetuses with cervical and oropharyngeal masses, the localization and characteristics of the mass, its relationship to the airway and the presence of polyhydramnios seems to be major factors determining EXIT approach and clinical outcome. In our series, the presence of polyhydramnios, 


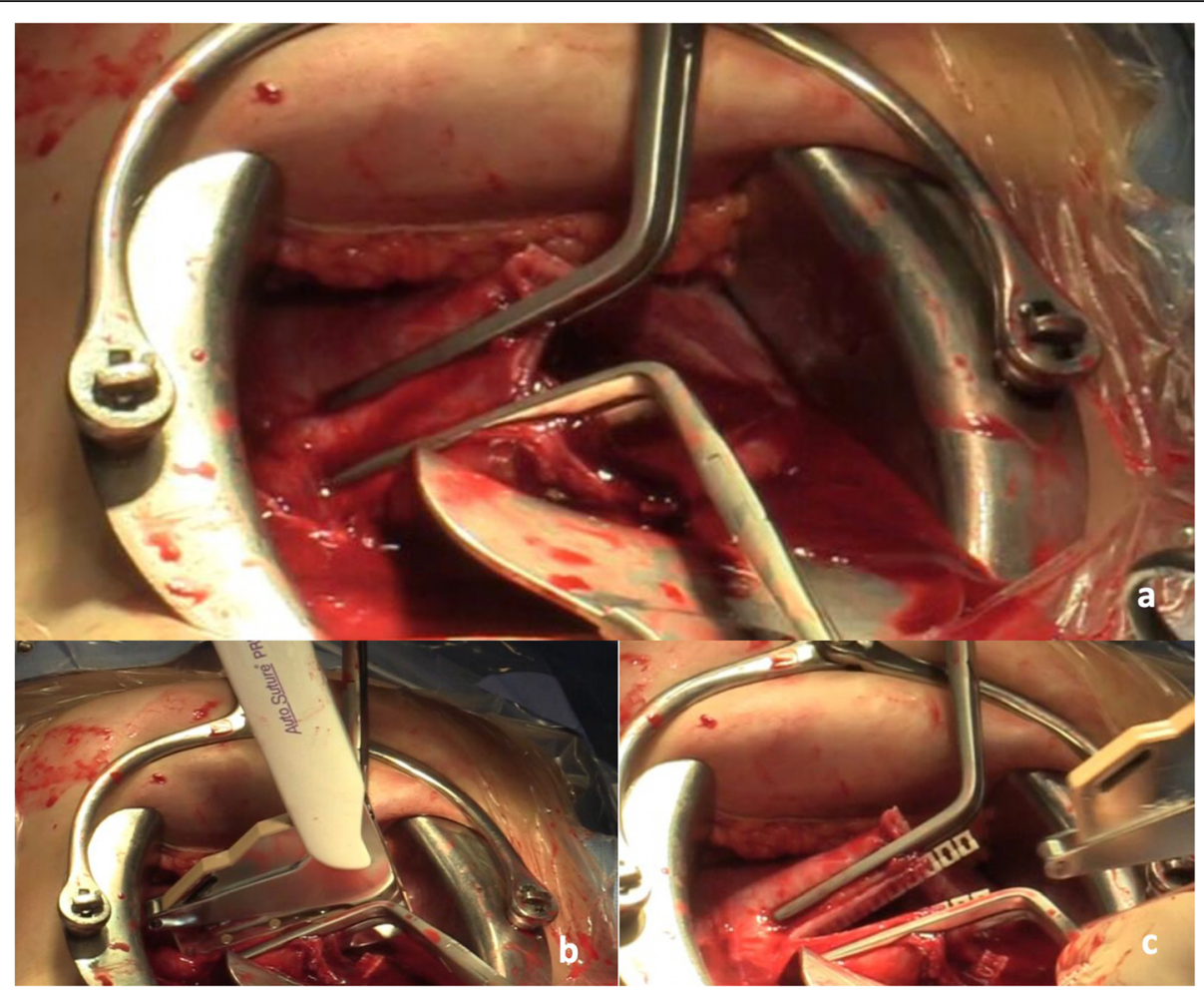

Fig. 1 Access to the uterine cavity and amniotic sac: After a low transverse laparotomy and once the uterus is exposed, intraoperative sterile ultrasonography is used to map the position of the placenta and the fetus. Then the access to the uterine cavity and the amniotic sac is made using our atraumatic Uterine Progressive Distractor (a), followed by Satinsky vascular clamps (b) and a stapling device (Premium Poly Cs-57 Autosuture $^{\oplus}$ ) (c) to minimize uterine bleeding to allow a safe maternal exit time

which may be related to premature labor and/or a neonatal poorer prognosis [6], was consistent with the existence of severe extrinsic obstruction of fetal airway.

When EXIT surgery is performed by a multidisciplinary trained team using a meticulous atraumatic access to the uterine cavity, the perinatal outcome is greatly improved, being a safe technique for mother and fetus.

\section{Abbreviations}

EXIT: Ex-Utero Intrapartum Treatment; MRI: Magnetic Resonance Imaging

\section{Acknowledgements}

All persons that contributed to this study are listed authors and meet the criteria for authorship.

\section{Authors' contributions}

LG-D, AC, JCA, AP and GA contributed to the study conception and design. Material preparation, data collection and analysis were performed by LG-D, $A C$ and GA. The first draft of the manuscript was written by LG-D and all authors commented on previous versions of the manuscript. All authors contributed to the drafting or revising of the manuscript, approved this final version to be published, and are willing to take public responsibility for the accuracy and integrity of its content.

\section{Funding}

There was no funding for this study.

\section{Availability of data and materials}

The datasets used during the current study are available from the corresponding author on reasonable request.
Ethics approval and consent to participate

Written informed consent was obtained from the patients for publication of this report and any accompanying images. A local ethics committee ruled that no formal ethics approval was required in this particular case since it did not contain any identifiable information.

\section{Consent for publication}

The five patients provided written informed consent for the publication of potentially identifying images and clinical details.

\section{Competing interests}

The authors declare that they have no competing interests.

\section{Author details}

'Department of Materno-Fetal Medicine, Genetics, and Reproduction, Institute of Biomedicine of Seville (IBIS), Hospital Universitario Virgen del Rocio/CSIC/University of Seville, Avda. Manuel Siurot s/n ES-41013, Seville, Spain. ${ }^{2}$ Fetal, IVF and Reproduction Simulation Training Centre (FIRST), Seville, Spain. ${ }^{3}$ Department of Pediatric Surgery, Hospital Universitario Gregorio Marañón, Madrid, Spain. ${ }^{4}$ Department of Neonatology, Hospital Universitario Virgen del Rocio, Seville, Spain. ${ }^{5}$ Centre for Biomedical Network Research on Rare Diseases (CIBERER), Seville, Spain.

Received: 28 April 2020 Accepted: 30 September 2020

Published online: 07 October 2020

\section{References}

1. Hedrick HL. Ex utero intrapartum therapy. Semin Pediatr Surg. 2003;12(3): 190-5.

2. Liechty KW. Ex-utero intrapartum therapy. Semin Fetal Neonatal Med. 2010; 15(1):34-9. 
3. Hirose S, Farmer DL, Lee H, Nobuhara KK, Harrison MR. The ex utero intrapartum treatment procedure: looking back at the EXIT. J Pediatr Surg. 2004;39(3):375-80.

4. García-Díaz L, de Agustín JC, Ontanilla A, Marenco ML, Pavón A, Losada A, Antiñolo G. EXIT procedure in twin pregnancy: a series of three cases from a single center. BMC Pregnancy Childbirth. 2014;14:252

5. Shih JC, Hsu WC, Chou HC, Peng SS, Chen LK, Chang YL, Hsieh FJ. Prenatal three-dimensional ultrasound and magnetic resonance imaging evaluation of a fetal oral tumor in preparation for the ex-utero intrapartum treatment (EXIT) procedure. Ultrasound Obstet Gynecol. 2005;25(1):76-9.

6. Lazar DA, Cassady Cl, Olutoye OO, Moise KJ Jr, Johnson A, Lee TC, Cass DL. Tracheoesophageal displacement index and predictors of airway obstruction for fetuses with neck masses. J Pediatr Surg. 2012;47(1):46-50.

7. Harrison MR, Adzick NS, Flake AW, VanderWall KJ, Bealer JF, Howell L, Farrell JA, Filly RA, Rosen MA, Sola A, Goldberg JD. Correction of congenital diaphragmatic hernia in utero VIII: response of the hypoplastic lung to tracheal occlusion. J Pediatr Surg. 1996;31(10):1339-48.

8. Hirose S, Harrison MR. The ex utero intrapartum treatment (EXIT) procedure. Semin Neonatol. 2003;8(3):207-14.

9. Marwan A, Crombleholme TM. The EXIT procedure: principles, pitfalls, and progress. Semin Pediatr Surg. 2006;15(2):107-15.

10. Olutoye OO, Olutoye OA. EXIT procedure for fetal neck masses. Curr Opin Pediatr. 2012;24(3):386-93.

11. Tanaka M, Sato S, Naito H, Nakayama H. Anaesthetic management of a neonate with prenatally diagnosed cervical tumour and upper airway obstruction. Can J Anaesth. 1994:41(3):236-40.

12. Schwartz MZ, Silver H, Schulman S. Maintenance of the placental circulation to evaluate and treat an infant with massive head and neck hemangioma. J Pediatr Surg. 1993;28:520-2.

13. Schulman SR, Jones BR, Slotnick N, Schwartz MZ. Fetal tracheal intubation with intact uteroplacental circulation. Anesth Analg. 1993;76(1):197-9.

14. Kelly MF, Berenholz L, Rizzo KA, Greco R, Wolfson P, Zwillenberg DA. Approach for oxygenation of the newborn with airway obstruction due to a cervical mass. Ann Otol Rhinol Laryngol. 1990;99(3 Pt 1):179-82.

15. Levine AB, Alvarez M, Wedgwood J, Berkowitz RL, Holzman I. Contemporary management of a potentially lethal fetal anomaly: a successful perinatal approach to epignathus. Obstet Gynecol. 1990:76(5 Pt 2):962-6.

16. Kornacki J, Szydłowski J, Skrzypczak J, Szczepańska M, Rajewski M, Koziołek A, Gaca M, Wender-Ożegowska E. Use of ex utero intrapartum treatment procedure in fetal neck and high airway anomalies - report of four clinical cases. J Matern Fetal Neonatal Med. 2019;32(5):870-4.

17. Too S, Ahmad Sarji S, Yik Y, Ramanujam T. Malignant epignathus teratoma. Biomed Imaging Interv J. 2008;4(2):e18.

18. Laje P, Peranteau WH, Hedrick HL, Flake AW, Johnson MP, Moldenhauer JS, Adzick NS. Ex utero intrapartum treatment (EXIT) in the management of cervical lymphatic malformation. J Pediatr Surg. 2015;50(2):311-4.

19. Dighe MK, Peterson SE, Dubinsky TJ, Perkins J, Cheng E. EXIT procedure: technique and indications with prenatal imaging parameters for assessment of airway patency. Radiographics. 2011;31(2):511-26.

20. Kalache KD, Masturzo B, Pierro A, Peebles D, Chitty LS. Prenatal evaluation of fetal neck masses in preparation for the EXIT procedure: the value of pulmonary Doppler ultrasonography (PDU). Prenat Diagn. 2001;21(4):308-10.

21. Novoa RH, Quintana W, Castillo-Urquiaga W, Ventura W. EXIT (ex utero intrapartum treatment) surgery for the management of fetal airway obstruction: A systematic review of the literature [published online ahead of print, 2020 Feb 19]. J Pediatr Surg. 2020;50022-3468(20):30111-1.

\section{Publisher's Note}

Springer Nature remains neutral with regard to jurisdictional claims in published maps and institutional affiliations.

Ready to submit your research? Choose BMC and benefit from:

- fast, convenient online submission

- thorough peer review by experienced researchers in your field

- rapid publication on acceptance

- support for research data, including large and complex data types

- gold Open Access which fosters wider collaboration and increased citations

- maximum visibility for your research: over $100 \mathrm{M}$ website views per year

At $\mathrm{BMC}$, research is always in progress.

Learn more biomedcentral.com/submissions 